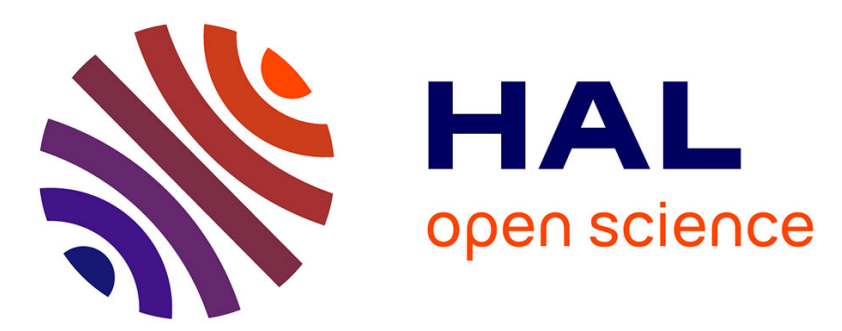

\title{
A Comparative Analysis Between BPMN and ISO 19440 Modeling Language Constructs
}

\author{
Ângela Teresa Rochetti, Renato De Campos
}

\section{To cite this version:}

Ângela Teresa Rochetti, Renato De Campos. A Comparative Analysis Between BPMN and ISO 19440 Modeling Language Constructs. IFIP International Conference on Advances in Production Management Systems (APMS), Sep 2016, Iguassu Falls, Brazil. pp.256-263, 10.1007/978-3-319-51133-

7_31.hal-01615800

\author{
HAL Id: hal-01615800 \\ https://hal.inria.fr/hal-01615800
}

Submitted on 12 Oct 2017

HAL is a multi-disciplinary open access archive for the deposit and dissemination of scientific research documents, whether they are published or not. The documents may come from teaching and research institutions in France or abroad, or from public or private research centers.
L'archive ouverte pluridisciplinaire HAL, est destinée au dépôt et à la diffusion de documents scientifiques de niveau recherche, publiés ou non, émanant des établissements d'enseignement et de recherche français ou étrangers, des laboratoires publics ou privés. 


\title{
A Comparative Analysis Between BPMN and ISO 19440 Modeling Language Constructs
}

\author{
Ângela Teresa Rochetti* and Renato de Campos \\ São Paulo State University, Bauru, Brazil \\ *angela.rochetti@yahoo.com \\ rcampos@feb.unesp.br
}

\begin{abstract}
Enterprise modeling is a tool that can be used for simple objectives, such as understanding how a part of the enterprise works, to more complex objectives, such as information flow for the computerized systems, or knowledge storage in an organization. There are several languages proposed for enterprise modeling, such as BPMN, CIMOSA and UML. They have different characteristics, advantages and disadvantages. This paper presents a comparison in relation to representation capacity between the ISO 19440 language constructs and the BPMN notation based on their constructors and icons. The analysis shows that BPMN has less representation capacity, showing differences between one language for modeling various aspects in an enterprise (ISO 19440) and a notation (BPMN) which focuses on process modeling and has few constructs for representing other aspects such as an enterprise's resources and organization..
\end{abstract}

Keywords: Process modeling · Enterprise $\cdot$ Modeling $\cdot$ BPMN · ISO 19440

\section{Introduction}

For business enterprise be understood and integrated, it is necessary for them to be systematically represented as models [1]. They differs in the number of details according to the perspective of the person, where each person will naturally have a slight difference in the point of view of enterprise objectives and visions $[2,3]$. Enterprise modeling languages define generic modeling constructors for enterprise modeling adapted to the needs of people who create and use enterprise models [4]. There are several languages and notations for enterprise modeling, such as BPMN, UML and CIMOSA, among others [5,6,7]. ISO 19440 defines a generic set of language constructs for enterprise modeling with common semantics, capable of unifying models developed by different people at various stages of development of business models, which support decision-making, monitoring and control. New proposals have emerged aimed at enterprise business modeling and management $[8,9]$. Business Process Management (BPM) is gaining force, which is normally supported by use of modeling tools based on Business Process Modeling Notation (BPMN) [10]. Since several alternative proposals exists, it 
becomes important to know the characteristics, advantages, disadvantages and representation capacities of each for appropriate use.

This paper presents a comparison between ISO 19440 language constructors and BPMN notation. Thus, below we give a brief description of ISO 19440 constructs and BPMN. Then, a comparative analysis is presented and final considerations.

\section{ISO 19440 Modeling Constructs}

The standard ISO 19440 supports enterprise modeling, and was created based on developments of modeling techniques as CIMOSA, GRAI, GERAM, among others [11]. His last update was in 2007, and was prepared by the European Committee for Normalization (CEN), Technical Committee CEN / TC 310, in collaboration with Technical Committee ISO / TC 184 (Integration and Industrial Automation Systems), Subcommittee SC 5 (Architecture and Structures Integration and Communication). They were also received contributions from members of the Task Force on Enterprise Integration IFAC / IFIP, the consortium CIMOSA, and the European project ATHENA [12]. ISO 19440 defines generic constructors to a modeling language based on enterprise business processes, described on templates. These constructs include generic attributes predefined in this standard, however, other attributes can be added for a particular need. They can be categorized according to their main views:

- Function and process-related: Domain, Business Process, Enterprise Activity, Event, Functional Operation, and Behavioral Rules;

- Information-related: Enterprise Object, Enterprise Object View, Order, Product;

- Resource-related: Capability, Operational Role, Resource, and Functional Entity;

- Organization-related: Person Profile, Organizational Role, Organization Unit, and Decision Centre.

These constructs are described below, based on the standard itself [12]:

- Domain: Represents the boundary and the content of an enterprise or a portion of an enterprise for which an enterprise model is to be created.

- Business Process: Represents all or part of the domain functionalities, its internal structure and its dynamic behavior. A Business Process construct shall describe the functionalities needed to produce a desired result that satisfies business objectives.

- Behavioral Rules: The purpose of the behavioral rules is to identify the start of the main Business Process, and describe the logical sequencing relationships of constituent Business Processes or Enterprise Activities, or both.

- Enterprise Activity: Represents the part of process functionality that is needed to realize a basic task within a Business Process. They are the lowest level constituents of a Business Process defined according to required user objectives for control. 
- Functional Operation: Represents a part of the functionality of an Enterprise Activity, which has been decomposed into a number of transformation functions.

- Event: The purpose of the Event construct is to capture reason, origin and destination of an event. An Event shall represent the initiation of a state change in the enterprise or its environment, to be used to initiate the execution of one or more processes.

- Enterprise Object: Describe those characteristics (attributes and relational structure) and to provide for selection of relevant parts (Object Views) that are to be identified in the modeling process and used during the operational phase.

- Enterprise Object View: The purpose is to enable the identification of relevant attributes from a particular Enterprise Object as required by a Domain, a Business Process, or an Enterprise Activity for the definition of their inputs and outputs. It shall represent a subset of the descriptive attributes of an Enterprise Object.

- Product: This construct describes all intermediate stages of product life cycles with regard to both material and informational aspects. It is a very important construct because fabrication and sale of products are the aim of the enterprise.

- Order: Order construct describes what has to be done, which products are to be produced, which resources are to be used, and what purchases have to be made.

- Resource: The purpose of the Resource construct is to classify and describe in terms of capabilities all material and informational aids in an enterprise, such as machining equipment, tools and facilities, documents and files containing geometrical, material and informational characteristics, related the execution of Enterprise Activities.

- Capability: Represents the elements of both the capabilities required by an Enterprise Activity and those provided by a resource.

- Functional Entity: Describe the Operational Roles and Capabilities provided by the Functional Entity as well as the set of functional operations that can be assigned to it and which it can execute in a quasi-autonomous mode.

- Person Profile: Describe the human skill profiles available to serve the assigned organizational and operational tasks and to fulfill the responsibilities associated. Organizational Unit: This construct describes an identifiable entity together with its position relative to other such entities in the enterprise organizational structure.

- Decision Centre: The purpose of the Decision Centre construct is to describe its contents (in terms of classes of decisional functions) and its relations to other Decision Centers (the related decisional and information flow) and to Organizational Units.

- Organizational Role: Describes the skill profile required to serve organizational responsibilities and to fulfill those responsibilities. A skill profile shall be a list of predefined or user-defined human organizational skills, described 
in terms appropriate to the user of those skills and understandable by the person providing them.

- Operational Role: Skill profile required and provided to undertake the defined operational tasks. It shall be a list of predefined or user-defined human operational skills, described to the user of those skills and understandable to the person.

\section{Business Process Management Notation (BPMN)}

Business Process Management (BPM) gathers business management and information technology promoting the integration and improvement of the organizations' business processes using methods, techniques and tools to model, publish, control and analyze operational processes involving diverse people and systems. BPM's objectives are typically [6]: obtain knowledge about the enterprise's business processes; use this knowledge of business processes in the reengineering project of business processes to optimize the operation; facilitate enterprise decision making; support the interoperability of business processes. In the context of BPM, one of the main characteristics is the Business Process Management System (BPMS) modeling tools, which usually adopt Business Process Modeling Notation (BPMN). The latter refers to a series of standard icons for designing processes, which facilitates user understanding [13].

BPMN's main objectives are to standardize business process modeling, expand modeling resources and create a formal mapping between high-level modeling and execution languages. BPMN create a simple mechanism to develop business process models while also ensuring the inherent complexity of the processes. This notation was developed by the Business Process Management Initiative (BPMI) in May 2004, and in June 2005, BPMI merged with the Object Management Group (OMG). In February 2006, OMG adopted and officially published version 1.0 [14].

One of BPMN's major benefits is the reuse of code, because, according to the author, when enterprises construct models of components that represent a specific implementation, they can be stored in model libraries that can be used in the future by another similar application by just importing the model's code [6]. BPMN provides a basic set of diagrams to represent business processes in a simple manner, but that at the same time are capable of controlling the inherent complexity of the business processes. This basic set is divided into four categories [14]: Connection Objects (Fig. 1); Flow Objects (Fig. 2); Swimlanes (Fig. 3); Artifacts (Fig. 4).

\section{Comparisons Between ISO 19440 and BPMN}

\subsection{Procedures for Analyses and Comparisons}

After introducing the ISO 19440 language and BPMN notation, a comparative analysis is conducted. The analysis is conducted as per functional, information, 


\begin{tabular}{|c|c|c|}
\hline Element & Description & Icon \\
\hline $\begin{array}{c}\text { Sequence } \\
\text { Flow } \\
\end{array}$ & $\begin{array}{l}\text { Used to show the order (sequence) in which activities will be } \\
\text { carried out in a process. }\end{array}$ & $\longrightarrow$ \\
\hline $\begin{array}{c}\text { Message } \\
\text { Flow }\end{array}$ & $\begin{array}{l}\text { Used to show the message flow between two different } \\
\text { participants who send and receive them. }\end{array}$ & $-----\rightarrow$ \\
\hline Association & $\begin{array}{l}\text { Used to associate data, text, and other artificts with flow } \\
\text { objects. Associations are used to show inputs and outputs of } \\
\text { activities. }\end{array}$ & $\cdots \cdots \cdots$ \\
\hline
\end{tabular}

Fig. 1. Connection Objects. (Source: Adapted from BPMI [14])

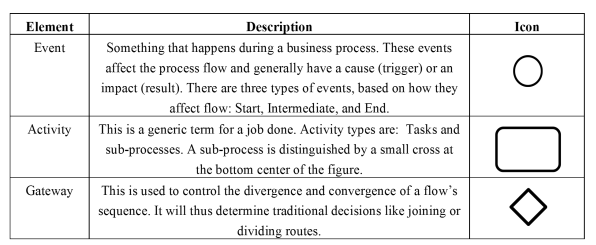

Fig. 2. Flow Objects. (Source: Adapted from BPMI [14])

\begin{tabular}{|c|c|c|}
\hline Element & Description & Icon \\
\hline Pool & $\begin{array}{c}\text { A pool represents a participant in a process. It acts as } \\
\text { a graphic container to divide a set of activities from } \\
\text { other pools, generally in the context of Business to } \\
\text { Business situations. }\end{array}$ \\
\hline Lane & $\begin{array}{c}\text { A lane is a subdivision in a pool used to organize and } \\
\text { categorize activities. }\end{array}$ & \\
\hline
\end{tabular}

Fig. 3. Swimlanes. (Source: Adapted from BPMI [14])

\begin{tabular}{|c|c|c|}
\hline Element & Description & Icon \\
\hline $\begin{array}{c}\text { Data } \\
\text { Objects }\end{array}$ & $\begin{array}{c}\text { A data object is a mechanism to show how data is } \\
\text { requested or produced by activities. They are } \\
\text { connected to activities with the associations. }\end{array}$ \\
\hline Group & $\begin{array}{c}\text { A group is represented by a rectangle and it can be } \\
\text { used for documentation or analysis purposes. }\end{array}$ \\
\hline Annotations & $\begin{array}{c}\text { Annotations are mechanisms for providing additional } \\
\text { information to the reader of a BPMN diagram }\end{array}$ \\
\hline
\end{tabular}

Fig. 4. Artifacts Objects. (Source: Adapted from BPMI [14])

resource and organization views. The synthesis of these comparisons is shown in Fig. 5, and the respective discussions and analyses are shown in sequence. It is understood that class objects in ISO 19440 and icons in BPMN are constructors of the respective languages. The classification used in the comparison between modeling language constructors (and their construction elements) was conducted in accordance with the 'correspondence' between constructors. The analysis is made in relation to how much a specific constructor conceptually representing an object or typical entity of an enterprise in a language corresponds to a constructor in the other language (or notation). These correspondences are classified as: 
- Strong, for when constructors are conceptually very similar, corresponding to the representation of the same object or entity in a model, admitting a few minor and insignificant differences in this representation;

- Average, for when constructors are conceptually similar, corresponding to the representation of the same object or entity, however with significant differences in representation of the same concept, for example, in the case of constructors that have a large number of elements of different information (or attributes);

- Weak, for when constructors are conceptually little similar, not exactly representing the same object, but having aspects related to the objects being represented.

When a language does not have a constructor representing some aspect of a constructor of another language, the relative space in the box is kept blank.

\subsection{Analyses and Comparisons}

The framework of Fig. 5 shows the name of the languages being compared and the respective classifications of correspondences, followed by analyses and observations. For Business Process, Event, Enterprise Activity and Functional Operation, constructors of ISO 19440, it was identified strong correspondences (very similar) in BPMN.

The Business Process constructors in ISO 19440 can be represented in BPMN by the Sub-Process constructor, a specific case of Activity.

The Domain construct in ISO 19440 could be represented in a weak similar manner with Group notation, grouping a certain number of processes from an enterprise's functional area in the model (which could be a department or not).

The Domain Relationship could be represented by a set of Events, Messages or Data Object. The ISO 19440 Behavior Rule construction element can be represented by the combination of Events and Flows in BPMN, being considered of average correspondence (similar). Although it is possible to conceptually represent the same object (behavior rules for processes) with these symbols, behavior rules in ISO 19440 have greater flexibility in representation in terms of logical expressions and are not restricted to BPMN's graphic representations.

Information view constructors in ISO 19440 has correspondence average (little similar) with Artifacts in BPMN, being more similar to Data Objects. In BPMN, an artifact represents a datum, however, without interfering in the flow.

Weak correspondences were also considered between ISO 19440's Organization unit constructors and Pool and Lane element (since it is a sub-division in BPMN), and between ISO 19440's Decision Centre and the Lane element (which be used as a container to separate a decision activities). Then, BPMN symbols represent few aspects related to organization.

In the comparisons between ISO 19440 and the BPMN language, a synthesis analysis show that four of six ISO 19440's constructors in the Function View have a strong correspondence in BPMN, and two have average correspondence. For the Information View, the constructors have average correspondence. The ISO 


\begin{tabular}{|c|c|c|}
\hline ISO 19440 & BPMN & Classification of Correspondence \\
\hline \multicolumn{3}{|c|}{ Function View } \\
\hline Domain & Group & Weak \\
\hline Business Process & Sub-Processes [Activity] & Strong \\
\hline Event & Event & Strong \\
\hline Behavior Rule & Gateway and Connections & Average \\
\hline Enterprise Activity & Tasks [Activity] & Strong \\
\hline Functional Operation & Atomic Task [Activity] & Strong \\
\hline \multicolumn{3}{|c|}{ Information View } \\
\hline Enterprise Object View & [Data Object] & Average \\
\hline Enterprise Object & [Data Object] & Average \\
\hline Product & [Data Object] & Average \\
\hline Order & [Data Object] & Average \\
\hline \multicolumn{3}{|c|}{ Resource View } \\
\hline Capability & - & - \\
\hline Operational Role & - & - \\
\hline Resource & - & - \\
\hline Functional Entity & - & - \\
\hline \multicolumn{3}{|c|}{ Organization View } \\
\hline Organization Unit & Pool [Lane] & Weak \\
\hline Decision Centre & [Lane] & Weak \\
\hline Person Profile & - & - \\
\hline Organizational Role & - & - \\
\hline
\end{tabular}

Fig. 5. Comparison between ISO 19440 and BPMN constructors

19440 constructors in the Resources View do not have any correspondence, and in the Organization View, two of its four constructors have a weak correspondence.

Since BPMN focuses on processes, it would be expected for this notation to be fitting for process modeling (functional and business related aspects). Thus, from the comparisons, it can be perceived that it minimally represents some aspects of the information and organization views, and that it does not explicitly represent aspects of the resources view.

\section{Final Considerations}

This paper presented a comparison in relation to representation capacity between the ISO 19440 language and the BPMN notation based on their constructors. The analysis shows that BPMN has less representation capacity, showing differences between one language for modeling various aspects in an enterprise (ISO 19440) and a notation (BPMN) which focuses on process modeling and has few constructs for representing other aspects such as an enterprise's resources and organization.

In BPMN notation, the basis for representing enterprise aspects is the graphic elements. Although BPMN has a significant number of graphic symbols, these constructors do not present detailed templates, like ISO 19440.

Although ISO 19440 defines a larger and much richer set of modeling constructors, on the other hand, a standard for the graphic representation of its main 
constructors is lacking. The graphic representation could provide a first understanding of the model, and then moving on to an understanding of details using templates that refer to its classes of objects and description elements (properties). The procedure used for analyses and comparisons employs a certain degree of subjectivity, and if more detailed comparisons are wanted, another technique must be used. However, the comparison and analysis in this paper will help users or analysts identify some gaps and correspondences that eventually permit discarding or classifying the languages in relation to some modeling objective, or for needs in terms of some specific view (functional, information, resources or organization), or a specific level of detail.

\section{References}

1. Kalpic, B., Bernus, P.: Business Process Modelling in Industry-the Powerful Tool in Enterprise Management. Computers in Industry 47(3), 299-318 (2002)

2. Eriksson, H.E., Penker, M.: Business Modeling With UML: Business Patterns at Work. Business Patterns at Work (2000)

3. Doebeli, G., Fisher, R., Gapp, R., Sanzogni, L.: Using BPM Governance to Align Systems and Practice. Business Proc. Manag. J. 17(2), 184-202 (2011)

4. Force, I.I.T.: GERAM: Generalised Enterprise Reference Architecture and Methodology. IFIP-IFAC Task Force on Architectures for Enterprise Integration March Version 1(3) (1999)

5. Mertins, K., Jochem, R.: Architectures, Methods and Tools for Enterprise Engineering. International Journal of Production Economics 98(2), 179-188 (2005)

6. Minoli, D.: Enterprise Architecture A to Z: Frameworks, Business Process Modeling, SOA, and Infrastructure Technology. Auerbach Publications, T. \& F. Group, New York (2008)

7. Vernadat, F.: Enterprise Modeling and Integration, Principles and Applications. Chapman \& Hall, London (1996)

8. McCormack, K., Willems, J., Van den Bergh, J., Deschoolmeester, D., Willaert, P., Indihar Štemberger, M., Škrinjar, R., Trkman, P., Bronzo Ladeira, M., Paulo Valadares de Oliveira, M., et al.: A Global Investigation of Key Turning Points in Business Process Maturity. Business Proc. Manag. J. 15(5), 792-815 (2009)

9. Palmberg, K.: Experiences of Implementing Process Management: A Multiple-case Study. Business Proc. Manag. J. 16(1), 93-113 (2010)

10. Kohlbacher, M.: The Effects of Process Orientation: A Literature Review. Business Proc. Manag. J. 16(1), 135-152 (2010)

11. Carnaghan, C.: Business Process Modeling Approaches in the Context of Process Level Audit Risk Assessment: An Analysis and Comparison. International Journal of Accounting Information Systems 7(2), 170-204 (2006)

12. International Organization for Standardization: ISO 19440:2007 - Enterprise Integration (2007)

13. ABPMP: Guide to the Business Process Management Common Body of Knowledge (2013)

14. BPMI: http://www.bpmn.org/Documents/BPMN_V1-0_May_3_2004.pdf 